\title{
Editorial Introduction: Towards a More Humanistic Management
}

In one of his books, Peter Drucker, considered by many as the father of modern management, presented these rhetorical questions: "What is management? Is it a bag of techniques and tricks? A bundle of analytical tools like those taught in business schools? (1990, pp. 220-221). His answer was unequivocal: "Management is about human beings. Its task is to make people capable of joint performance, to make their strengths effective and their weaknesses irrelevant. This is what organization is about, and it is the reason that management is the critical, determining factor" (1990, p. 221).

However, then and now, in many business schools, with respectable exceptions including that of my own school, analytical tools are still central, and a certain reductionism in the consideration of the human is still dominant (Ghoshal, 2005). Underlying such tools, there are theories, such as Agency Theory and Transaction Cost Economics, strongly anchored in the economic paradigm.

A New Manifesto for Management was presented at the turn of the millennium. Its authors wrote: "between the sound logic of efficiency and the harsh reality of human frailties and pathologies, it is no wonder that the dominant doctrine focuses managers' attention almost exclusively on concerns of appropriation and control. The resulting pathological economic role for companies and individuals should also be no surprise. It follows naturally from the premise that 'markets rule' that any and all failures to heed the market's corrective discipline are likely to be futile for firms and individuals and inefficient for society" (Ghoshal et al., 1999, p. 12). The current financial crisis confirms these words and makes a revision of the limits of the "market rule" urgent and also compels us to re-think the role of management and its dominant economic paradigm.
In the economic paradigm, the human being is considered under the narrow view of the homo oeconomicus ("economic man") model. This model gives to the individual a fictional character describing him/her as a rational being, with self-interest in maximizing his or her utilities, generally lead by desires for wealth, personal satisfaction, and to avoid unnecessary labor. Rational is understood as capacity for instrumental rationality, that is, for judging the comparative efficacy of a means to obtain an end.

Other views enrich the narrow view of homo oeconomicus. Psychology and sociology have made interesting contributions for a better understanding of how human behavior is and how the social performance of groups occurs. The descriptions provided by these sciences are apparently "free values", since they are based only on observable and measurable facts. However, the underlying conceptual approach of social sciences applied to management is that human beings are "human resources" for profits, and people are seen through this lens. Seeing the individual and the organization from a political perspective is another possibility to enlarge the landscape. These perspectives of the individual make interesting contributions, but their visions of human nature are quite incomplete. Management is about human beings, which entails considering their intrinsic value and openness to flourishing in their humanity cannot be ignored.

Without doubt management should aim for efficiency, but management should also consider people in their fullness. Thus, a humanistic management, with a more accurate view of human nature, is a real challenge.

Re-thinking economics, business, and management from a humanistic perspective is a long-term goal, but some partial stages can contribute to this end. With these ideas in mind, we organized the 
15th IESE International Symposium on Ethics, Business and Society, seeking more humanistic models and practices for business and management. ${ }^{1}$ In excess of 80 papers were submitted to this biennial symposium, which took place in Barcelona, Spain on May 16-17, 2008. This special issue of the Journal of Business Ethics includes a selection of articles presented there after being refined and enriched through discussions and reviewer suggestions.

It begins with a set of articles, which from different perspectives propose the idea of going back to Aristotle to develop more humanistic models of economics, business, and management. Claus Dierksmeier and Michael Pirson, by analyzing the origins of economic philosophy, state that Aristotle's thought can help us to reorient the discourse regarding the role of corporations in society. More specifically, these scholars suggest that Aristotle's theory of household management can be applied to the management of modern corporations. Their main point is that the Aristotelian notions of chrematistike and oikonomia provide a basis to discuss the relationship between business and society and to draw important conclusions for business management.

Similarly, Benedetta Giovanola argues for the necessity of a sound ethical and anthropological foundation of economics and business, and emphasizes the importance of a correct understanding of human values and human nature for the sake of economics and of businesses themselves. For this purpose, she suggests that such ethical-anthropological bases of economics and business can be grasped by taking Aristotle's virtue ethics and Amartya Sen's capability approach as major reference points. She holds that an "Aristotelian economics of virtues", connected with the capability approach and its notion of human richness, can promote the shift to the concept of personhood, and can lead to a more "humanized" business, by fostering human flourishing, the enhancement of human capabilities, and the pursuit of a more humane development for each and every person.

A third article presents a model of collaborative entrepreneurship for a more humanistic management within and across communities of firms operating in complementary markets. Its authors, Hector Rocha and Raymond Miles, evaluate six studies of communities of organizations, and adopting an integrational approach, they propose an inter-organizational network model based on the assumptions about human motives and choice offered by Aristotle. In this way, they try to overcome the narrow set of assumptions about human nature, human relationships, and ethics adopted by the current inter-organizational models.

The following article, written by Po Keung Ip, explores whether and to what extent Confucianism as a resilient Chinese cultural tradition can be used as a sound basis of business practice and management model for Chinese corporations in the twenty-first century. Using the core elements of Confucianism, the paper constructs an ideal type of Confucian Firm. He describes the basic character of the Confucian Firm and expresses reservations about its moral legitimacy and relevance for today's China. He argues that the so-called "human-based" and "virtue-based" business practices rooted in local cultural heritage have been used as a Chinese attempt to respond to corporate social responsibility. However, Ip's analysis reveals some major negative elements in the Confucian Firm. He emphasizes familial collectivism, which, he says, creates severe obstacles. He argues that without instituting reasonable and effective norms, together with effective mechanisms to protect rights, a virtue-based Confucian Firm will fall short of meeting the daunting challenges of this century.

The three following articles focus on human work, which is indeed a key element of business and business management. The first is written by David Pastoriza, Miguel A. Ariño, and Joan E. Ricart. They focus on the concept of "ethical work context" as an influential antecedent of social capital in the firm. They discuss how this concept, which can be related to the notion of "humanizing culture", allows a broader comprehension of the concrete management practices and organizational dynamics that generate organizational social capital. They also argue that social capital, understood as a by-product of the ethical work context, results both from organizational design and ongoing managerial activity. They conclude that creating an ethical work context brings ethics and social capital into the realm of the general manager; a figure that has remained absent from social capital literature.

The second article related with work is written by Marjolein Lips-Wiersma and Lani Morris. They 
begin by considering the increasing interest for meaningful work over the past two decades, but at the same time, they point out that so far most research on meaningful work has focused on providing those who work in an organization with meaning and on managing it through leadership or organizational culture. They note that this approach contrasts sharply with the literature of the humanities, which suggests that meaningfulness does not need to be provided since the distinct feature of a human being is that he or she has an intrinsic "will to meaning". In addition, where research has been done based on a humanistic paradigm, it has often been quite fragmented. Their article presents a project carried out by the authors with the aim of addressing these gaps. They employ action research methodology to actively involve participants in the process of affirming and uncovering the meaningfulness of their work. The findings, which can contribute to humanizing business, show various sources of meaningful work and their relationship to each other, in addition to other significant points.

A third article deals with the conciliation of work and family. Gregorio Guitian deals with this topic from a Catholic Social Thought (CST) perspective. He explains that such a perspective, although inspired by Christian faith, employs a rational approach and often the CST documents are addressed to all people of good will. The author discusses the principles presented by CST related to work-family relationships. In addition, he argues that business responsibility to the employees' family should be considered as a part of Corporate Social Responsibility. He concludes by pointing out that current empirical research suggests that the application of these principles leads to a mutual enrichment of both business and family.

In the following article, Daniel Palmer makes a contribution focusing on leadership. He provides an approach to go into the ethical substance of leadership in depth. He argues that ethical issues of leadership actually arise at a number of different levels, and that it is important to distinguish between various diverse kinds of ethical issues that appear in the study of leadership. He identifies three levels the: individual morality of leaders, level of the means of their leadership, and level of the leadership mission itself. He considers that only by fully understanding all of the different levels of ethical analysis pertinent to business leadership, and the distinctive kind of issues that arise at each level, we can fully integrate normative studies of leadership into the field of leadership studies. He concludes by offering a model that incorporates these three levels of ethical analysis that can be used to study normative issues in leadership studies, and to better understand and integrate ethical issues into research, teaching, and training in leadership.

Also related with leadership is the article authored by Thomas Maak and Nicola M. Pless. They argue that business leaders should consider themselves as cosmopolitan citizens and "agents of world benefit", since they are not only business leaders, but also citizens of the world. They discuss the idea that business leaders are key actors and agents in establishing a global economy with a human face in an increasingly connected and interdependent world, and one with many global problems. In addition, they present some key features of a cosmopolitan business ethics to contribute to a better understanding of the responsibilities of business leaders in such a connected world.

In addition, related to the current global landscape and how to face the corresponding responsibilities the following article has been written by Heidi von Weltzien Hoivik and Domènec Melé. They begin by questioning whether a small- or medium-sized enterprise can become a global corporate citizen. The response is based on a case study of a Norwegian clothing company. This case illustrates how an SME can be very innovative in exercising corporate citizenship, without necessarily following the patterns of large multinational companies. Ethics of care and concern for specific aspects of the common good seem crucial as drivers, along with personal values, character, and leadership of the ownermanager of the company.

Davide Secchi's article analyzes social responsibility at the individual level, following the foot-steps of Boal and Peery (1985), who linked social responsibility with the cognitive structure underlying ethical analysis and the stakeholder perspective. Secchi attempts to overcome some limitations by presenting a general model of human cognition and a wider perspective than that of the early stakeholder approach. To conclude, social responsibility is a mechanism that allows individuals to maintain cognitive advantages and emerges when the same social channel is exploited for extended periods of time. 
Finally, a paper authored by Susanne Hartlieb and Bryn Jones, state that ethical labeling of products is essential for more sustainable and ethical business practices and an integral part of any humanization of business. However, they feel that the gradual "mainstreaming" of ethical initiatives such as "Fairtrade" may risk subsuming ethical goals within business participants' competitive and profitoriented logics. Their discussion is based on the findings obtained from a qualitative survey of 15 of the 26 main UK initiatives, in social justice, animal welfare, and environmental sustainability from the agriculture, food processing, timber, aquaculture, textiles, and personal care sectors. In addition, according to the authors, the contrasting perspectives revealed between rival labeling initiatives show that the scope and functions of labeling projects go beyond the manifest of the communication of information between producer and consumers, and actually introduce elements of socio-political regulation.

\section{Note}

1 This Symposium had certain continuity with the 14th, focused on integrating ethics into management
(Melé, 2008), a selection of articles presented at which was published in a special issue of the Journal of Business Ethics 78(3).

\section{References}

Drucker, P.: 1990, The New Realities (Mandarin, London).

Ghoshal, S.: 2005, 'Bad Management Theories are Destroying Good Management Practices', Academy of Management Learning E Education 4(1), 75-91.

Ghoshal, S., C. A. Bartlett and P. Moran: 1999, 'A New Manifesto for Management', Sloan Management Review 40(3), 9-20.

Melé, D.: 2008, 'Integrating Ethics into Management', Journal of Business Ethics 78(3), 291-297.

IESE Business School, University of Navarra, Barcelona, Spain E-mail:mele@iese.edu 